\title{
Glycolysis of waste flexible polyurethane foam
}

\author{
Chao-Hsiung $\mathrm{Wu}^{\mathrm{a}, *}$, Ching-Yuan Chang ${ }^{\mathrm{b}}$, Chien-Min Cheng ${ }^{\mathrm{a}}$, Hung-Chang Huang ${ }^{\mathrm{b}}$ \\ ${ }^{a}$ Department of Environmental Engineering, Da-Yeh University, Chang-Hwa 515, Taiwan \\ ${ }^{\mathrm{b}}$ Graduate Institute of Environmental Engineering, National Taiwan University, Taipei 106, Taiwan
}

Received 29 July 2002; received in revised form 18 November 2002; accepted 23 November 2002

\begin{abstract}
Glycolysis of flexible polyurethane (PU) was investigated to provide useful data for the recycling of waste cars. The glycolysis experiments were performed under atmospheric pressure and isothermal condition $\left(220^{\circ} \mathrm{C}\right)$. Diethylene glycol (DEG) and potassium acetate (KAc) were used as solvent and catalyst, respectively. The properties of glycolysis products were determined by analyzing the hydroxyl value, weight average molecular weight $\left(M_{\mathrm{w}}\right)$, viscosity, and the conversion $(\mathrm{X})$ of the $-\mathrm{NCOO}-$ functional group in PU. The results indicate that the adequate concentrations of DEG and KAc are about 150 and $1 \%$ of the mass of the PU and an adequate reaction time is $90 \mathrm{~min}$. Purification experiments on the glycolysis products were carried out in a stirred flask with a shell and tube condenser. The distilled materials were collected at the gas-phase temperature ranges of $<245,245-260,260-275$, $275-290$, and $>290{ }^{\circ} \mathrm{C}$. The polyol-containing products are mostly in the temperature range of $245-260{ }^{\circ} \mathrm{C}$. The recovery of polyolcontaining products can be achieved by the distillation of glycolysis products.

(C) 2003 Elsevier Science Ltd. All rights reserved.
\end{abstract}

Keywords: Glycolysis; Polyurethane; Recycling; Waste cars

\section{Introduction}

Flexible polyurethane (PU) is one of the principal components of a car. In Taiwan, the amount of flexible PU salvaged from the recycling of waste cars is about 9044 tons per year. Based on the current recycling frameworks promoted by the Republic of China Environmental Protection Administration, Taiwan, waste cars have been a significant resource. The major methods for treating waste PU include rebonding, regrind recycling, glycolysis, feedstock recycling, and energy recycling [13]. Some studies have revealed that a proper glycolysis process may be used to resolve the disposal problems of waste PU and obtain high quality polyols (raw materials of PU) from waste PU [1-6].

Many researchers have investigated the glycolysis of waste PU. Simioni and Modesti [7] investigated the glycolysis products of flexible PU foams at $190{ }^{\circ} \mathrm{C}$. Their results indicated that the use of ethylene glycol (EG) allowed the process to be carried out with high polymer/ glycol ratio (up to 4:1). A polyphasic product was

\footnotetext{
* Corresponding author. Tel./fax: + 886-4-8511331.

E-mail address: chwu@mail.dyu.edu.tw (C.-H. Wu).
}

obtained. The final product of the research met the main requirements for a material for general use in the preparation of reaction injection moulding PU. Modesti et al. [8] further explored the glycolysis of flexible PU foams in the presence of EG and an organometallic catalyst, under an inert environment and at the boiling temperature of EG. The low aromatic amine content products can be used in the production of new polymers, without separation or purification of the phases. Borda et al. [9] investigated the glycolysis of flexible PU foams and elastomers in the temperature range of 170 $180{ }^{\circ} \mathrm{C}$. The reagents used were glycols [EG, 1,2-propylene glycol, triethylene glycol, poly(ethylene glycol)] and diethanolamine. In their study, a reaction mechanism was proposed for the glycolysis of polyurethanes. The polyol component was separated from the twophase liquid mixture and could be used as an industrial adhesive. Troev et al. [10] investigated the chemical degradation of flexible PU foams by triethyl phosphate. The degradation temperature was $190{ }^{\circ} \mathrm{C}$. The results indicated that the flexible PU foams could be converted into liquid form by an exchange reaction between urethane group and ethoxy groups of phosphoric acid triethyl ester. The degraded products were phosphoruscontaining oligourethanes. 
Table 1

Some properties of flexible PU foam

\begin{tabular}{|c|c|c|}
\hline Item & Value & \\
\hline \multirow[t]{20}{*}{ Base polyol (\%) } & \multicolumn{2}{|l|}{ A1362: 71.43, E660: 23.81, XF417: 4.76} \\
\hline & \multicolumn{2}{|l|}{ A1362 } \\
\hline & Specific gravity & $1.029\left(25 / 25^{\circ} \mathrm{C}\right)$ \\
\hline & Viscosity at $25^{\circ} \mathrm{C}(\mathrm{cps})$ & 1300 \\
\hline & Flash point, open cup $\left({ }^{\circ} \mathrm{C}\right)$ & 244 \\
\hline & Average molecular weight & 6000 \\
\hline & Hydroxyl number $\left(\mathrm{mg} \mathrm{KOH} \mathrm{g}^{-1}\right)$ & $25-31$ \\
\hline & Water max. $(\%)$ & 0.08 \\
\hline & \multicolumn{2}{|l|}{ E660 } \\
\hline & Specific gravity & $1.0284\left(20 / 20^{\circ} \mathrm{C}\right)$ \\
\hline & Viscosity at $25^{\circ} \mathrm{C}(\mathrm{cps})$ & 930 \\
\hline & Flash point, open cup $\left({ }^{\circ} \mathrm{C}\right)$ & 243 \\
\hline & Average molecular weight & 4800 \\
\hline & Hydroxyl number (mg KOH g ${ }^{-1}$ ) & $33.3-36.7$ \\
\hline & Water max. $(\%)$ & 0.07 \\
\hline & \multicolumn{2}{|l|}{ XF417 } \\
\hline & Specific gravity & $1\left(25^{\circ} \mathrm{C}\right)$ \\
\hline & Viscosity at $25^{\circ} \mathrm{C}(\mathrm{cps})$ & 2000 \\
\hline & Hydroxyl number $\left(\mathrm{mg} \mathrm{KOH} \mathrm{g}^{-1}\right)$ & 53 \\
\hline & Water max. $(\%)$ & 0.1 \\
\hline Proximate analysis (\%) & \multicolumn{2}{|c|}{ Moisture: 1.68, Ash: 3.38, Combustible: 94.94} \\
\hline Elemental analysis $(\%)$ & \multicolumn{2}{|c|}{ C: $64.42(0.09)^{\mathrm{a}}, \mathrm{H}: 8.58(0.014), \mathrm{N}: 4.82(0), \mathrm{O}^{\mathrm{b}}: 18.68, \mathrm{~S}: 0.03(0), \mathrm{Cl}: 0.09(0)$} \\
\hline Metal element analysis (ppbm) & \multicolumn{2}{|c|}{$\mathrm{Pb}: 9.86, \mathrm{Zn}: 410, \mathrm{Cr}: 3.35, \mathrm{Cd}: 1.34, \mathrm{Fe}: 4.62, \mathrm{Cu}, \mathrm{Mn}, \mathrm{Hg}, \mathrm{As}: \mathrm{ND}^{\mathrm{c}}$} \\
\hline
\end{tabular}

a Numbers in parentheses are standard deviations.

b $\mathrm{O} \%=(100-\mathrm{C}-\mathrm{H}-\mathrm{N}-\mathrm{S}-\mathrm{Cl}-$ moisture-ash $) \%$.

c Not detectable.

The glycolysis products of PU foams depend not only on the chemical-physical nature of polymers but also on the temperature, catalysts, type of glycols and glycol/polymer ratio $[3,11]$. The amine content in the recovered polyols is an important index for the reuse as feedstocks. Typically, at a temperature greater than $220{ }^{\circ} \mathrm{C}$, unwanted secondary reaction rates become competitive with respect to transesterification reactions, leading to a product with considerable amine content $[3,12]$. The use of potassium acetate is known to increase the amounts of amines in the glycolysis products of rigid PU foams [3]. Low amine content products may be obtained by adding chemical reagents to the glycolysis system $[5,8,13]$. The optimum range of temperature for $\mathrm{PU}$ glycolysis, when catalysts are present, has proved to be 180-220 ${ }^{\circ} \mathrm{C}$ [3]. The effects of temperature on the glycolysis products of elastomer PU waste have been investigated in the related literature [12]. In this study, a higher temperature $\left(220 \pm 5^{\circ} \mathrm{C}\right)$ was used to investigate the glycolysis of flexible PU from recycled cars. Diethylene glycol (DEG) and potassium acetate (KAc) were used as solvent and catalyst, respectively. The experiments for the glycolysis of flexible PU foam were performed under atmospheric pressure and in a stirred flask maintained at a constant temperature below the boiling point of DEG $\left(244-245^{\circ} \mathrm{C}\right)$. The effects of the reaction time $(t)$ and the concentrations of DEG and $\mathrm{KAc}$ in the mixture on the properties of glycolysis pro-
Table 2

Particle size distribution of flexible PU foam

\begin{tabular}{ll}
\hline Size range $(\mathrm{mm})$ & Mass \% \\
\hline $0-0.149$ & 4.31 \\
$0.149-0.297$ & 11.79 \\
$0.297-0.84$ & 74.86 \\
$0.84-2$ & 8.1 \\
$>2$ & 0.94 \\
\hline
\end{tabular}

ducts were investigated. The optimum reaction condition was obtained.

\section{Experimental}

Flexible PU foam from recycled cars was used in this study. The properties of the PU sample are listed in Table 1. The PU sample was dried and granulated to powder before glycolysis experiments. It was first dried at $100 \pm 1{ }^{\circ} \mathrm{C}$ for $24 \mathrm{~h}$ and then granulated by a pulverizer (Model CW-1, Hsiang Tai, Taiwan, 220 V, 5.5 A) with a 18 mesh $(1 \mathrm{~mm})$ screen. The PU powder $(30 \mathrm{~g})$ was sieved by a rotating and tapping shaker with a set of 10, 20, 50, and 100 mesh (2, 0.84, 0.297 and 0.149 $\mathrm{mm}$ ) screens for $30 \mathrm{~min}$. The particle size distribution of the pulverized flexible PU foam is shown in Table 2. The experiments consisted of three parts: glycolysis of 
flexible PU foam, purification of glycolysis products, and analysis of the products.

The process flow diagram of the glycolysis system was shown in the previous study $[14,15]$. The operating conditions and the glycolysis runs with different formulations of the solvent (DEG) and the catalyst (KAc) are listed in Table 3. A $2 \mathrm{dm}^{3}$ Pyrex flask reactor equipped with an agitator was used. The glycolysis experiments were performed under atmospheric pressure. Known masses of the solvent and catalyst were placed in the reactor first. The speed of the stirrer was set at $1050 \pm 50 \mathrm{rpm}$. The temperature of the heating mantle was set at $220 \pm 5^{\circ} \mathrm{C}$. When the temperature of the mixture (DEG and KAc) reached the specified value, the pulverized flexible PU foam was fed by a screw feeder. The feeding rate was $17-34 \mathrm{~g} \mathrm{~min}^{-1}$. The speeds of the stirrer and the feeding rate were set at constant values according to the rate of dissolution. Simultaneously, the feeding time and the reaction time (starting at the end of the feeding PU sample) were recorded. The glycolysis products were sampled at reaction intervals of $1,2,5,10,15,30,90,150,210,270$, 330 and $390 \mathrm{~min}$, respectively. The glycolysis products were collected after the reactor was cooled down to room temperature.

A $0.5 \mathrm{dm}^{3}$ flask with a shell and tube condenser was used as a still. The glycolysis products were distilled to obtain the polyol-containing liquid products. The dis- tilled materials were collected at various distillation temperature (gas-phase temperature) ranges of $<245$, 245-260, 260-275, 275-290, and $>290{ }^{\circ} \mathrm{C}$, respectively.

The properties of the glycolysis products, such as hydroxyl value (mg KOH $\mathrm{g}^{-1}$ ), conversion (X) of $-\mathrm{NCOO}$ - functional group in $\mathrm{PU}$, weight average molecular weight, and viscosity at different experimental conditions were analysed. The hydroxyl value was determined by the titration method (ASTM D2849 method B: pressure-bottle phthalation). Conversion of the $-\mathrm{NCOO}$ - functional group in $\mathrm{PU}$ was determined by Fourier transform infrared spectroscopy (FTIR, BIO-RAD, FTS-40) equipped with a DTGS detector. In the FTIR analysis, the solid sample was mixed with potassium bromide $(\mathrm{KBr})$ in a mass ratio of $1: 10$. The mixture was ground to powder and then pressed to a disc. If a sample was liquid, it was dropped and homogenized directly on the surface of the $\mathrm{KBr}$ disc. The disc was then analysed by FTIR. The weight average molecular weight was determined by gel permeation chromatography (GPC). The GPC system (TOSOH, Japan) consisted of a 10AT pumping system, a RID-10A detector, a SIC chromatocorder-12 integrator, and a Plgel Guard Column. The standard used for determining the $M_{\mathrm{w}}$ of the glycolysis products was polystyrene (TSK standard, TOSOH, Japan). The viscosity was determined by a Brookfield viscometer (model: DV-I). The elemental analysis for the flexible PU foam sample

Table 3

Glycolysis under different operating conditions

\begin{tabular}{|c|c|c|c|}
\hline Operating conditions: & $\begin{array}{l}\text { Solvent/catalyst: } \\
\text { Liquid-phase temperature }\left({ }^{\circ} \mathrm{C}\right) \text { : } \\
\text { Stirring speed }(\mathrm{rpm}) \text { : } \\
\text { Feeding rate }(\mathrm{g} \mathrm{min}-1) \text { : } \\
\text { System pressure }(\mathrm{atm}) \text { : }\end{array}$ & $\begin{array}{l}\mathrm{DEG} / \mathrm{CH}_{3} \mathrm{COOK}(\mathrm{KAc}) \\
215-225 \\
1000-1100 \\
17-34 \\
1\end{array}$ & \\
\hline Run number & DEG/PU (mass \%) & KAc/PU (mass \%) & Mass of PU (g) \\
\hline A011 & 250 & 5 & 168.01 \\
\hline A012 & 250 & 2 & 168.06 \\
\hline A013 & 250 & 1 & 168.02 \\
\hline A014 & 250 & 0.5 & 168.18 \\
\hline A015 & 250 & 0 & 168.05 \\
\hline A016 & 200 & 2 & 210.08 \\
\hline A017 & 200 & 1 & 210.08 \\
\hline A018 & 200 & 0 & 210.13 \\
\hline A021 & 150 & 5 & 280.01 \\
\hline A022 & 150 & 2 & 280.05 \\
\hline A 023 & 150 & 1 & 280.12 \\
\hline A024 & 150 & 0.5 & 280.07 \\
\hline $\mathrm{A} 025$ & 150 & 0 & 280.1 \\
\hline A026 & 100 & 2 & 420.01 \\
\hline A027 & 100 & 1 & 420.03 \\
\hline A028 & 100 & 0 & 420.06 \\
\hline A031 & 50 & 5 & 840.05 \\
\hline A032 & 50 & 2 & 840.04 \\
\hline A033 & 50 & 1 & 840.11 \\
\hline A034 & 50 & 0.5 & 840.01 \\
\hline $\mathrm{A} 035$ & 50 & 0 & 840.02 \\
\hline
\end{tabular}


was made with a Perkin-Elmer, Norwalk, CT 2400 elemental analyser. The heavy metals in the flexible PU sample were analysed by an inductively coupled plasmaatomic emission spectrometer (ICP-AES; Germany Kontron S-35). The mass of initial sample used for the analysis of heavy metals was $100 \mathrm{mg}$. The sample mixed with strong acids $\left(3 \mathrm{~cm}^{3} \mathrm{HNO}_{3}, 1 \mathrm{~cm}^{3} \mathrm{HClO}_{4}\right.$, and 1 $\mathrm{cm}^{3} \mathrm{HF}$ ) was digested at $170{ }^{\circ} \mathrm{C}$ for $4 \mathrm{~h}$. It was then diluted to $100 \mathrm{~cm}^{3}$ with pure $\mathrm{H}_{2} \mathrm{O}$ and analysed by the ICP-AES. The properties of the distilled materials were analysed by the same methods as those of the glycolysis products.

\section{Results and discussion}

\subsection{Properties of glycolysis products}

The variation in the hydroxyl value of the glycolysis products with different reaction times at DEG/ $\mathrm{PU}=150 \%$, for example, is shown in Fig. 1. They are about $460-780 \mathrm{mg} \mathrm{KOH} \mathrm{g}^{-1}$. It is noted that after a reaction time of $90 \mathrm{~min}$, the hydroxyl value reaches nearly constant values for all the experimental runs. The extent of PU glycolysis can also be observed from the conversion $(\mathrm{X})$ of the $-\mathrm{NCOO}$ - functional group in the urethane. Based on the dissociation energy, the aromatic ring in $\mathrm{PU}$ is more stable than the $-\mathrm{NCOO}-$ functional group and is not destroyed in the glycolysis temperature range. The conversion of the $-\mathrm{NCOO}-$ functional group in PU thus was estimated by the relative absorption intensity of the $-\mathrm{NCOO}-$ (at about $1720 \mathrm{~cm}^{-1}$ ) to that of the aromatic ring, $-\mathrm{Ar}$, (at about $1450 \mathrm{~cm}^{-1}$ ). The conversion of - NCOO- varies with the reaction time and concentrations of DEG and $\mathrm{CH}_{3} \mathrm{COOK}$ and is in the range of 30.3-98.9\% under the experimental conditions. The FTIR spectrum of the glycolysis products for $\mathrm{DEG} / \mathrm{PU}=150 \%$ and $\mathrm{KAc} /$ $\mathrm{PU}=1 \%$ is shown in Fig. 2. The absorption intensity of -NCOO- varies inversely with the reaction time. The variation in the conversion of $-\mathrm{NCOO}-$ with the reaction time at $\mathrm{DEG} / \mathrm{PU}=150 \%$, for example, is shown in Fig. 3. The conversions of the $-\mathrm{NCOO}-$ also reaches nearly constant values after a reaction time of $90 \mathrm{~min}$. Upon examining Figs. 1 and 3, the results suggest that an adequate reaction time is about $90 \mathrm{~min}$, which is also supported by the variation of the weight average molecular weight $\left(M_{\mathrm{w}}\right)$ with the reaction time (shown in Fig. 4). The $M_{\mathrm{w}}$ is in the range of 628-3952 for all the experimental runs. From Fig. 4, one notes that the $M_{\mathrm{w}}$ varies inversely with reaction time.

To check the effects of solvent and catalyst on the glycolysis, the variations in the hydroxyl value, the conversion of the $-\mathrm{NCOO}-$ group, $M_{\mathrm{w}}$, and viscosity with the concentration of KAc at $t=90 \mathrm{~min}$ are shown in Figs. 5-8. Higher hydroxyl values are obtained at higher DEG and KAc concentrations, which may be ascribed to the effects of DEG and KAc on the glycolysis. Because the hydroxyl value of pure DEG is 1057.3 $\mathrm{mg} \mathrm{KOH} \mathrm{g} \mathrm{g}^{-1}$ and the excess DEG is not separated from the glycolysis products, the hydroxyl value may be partly attributed to that of pure DEG. The hydroxyl

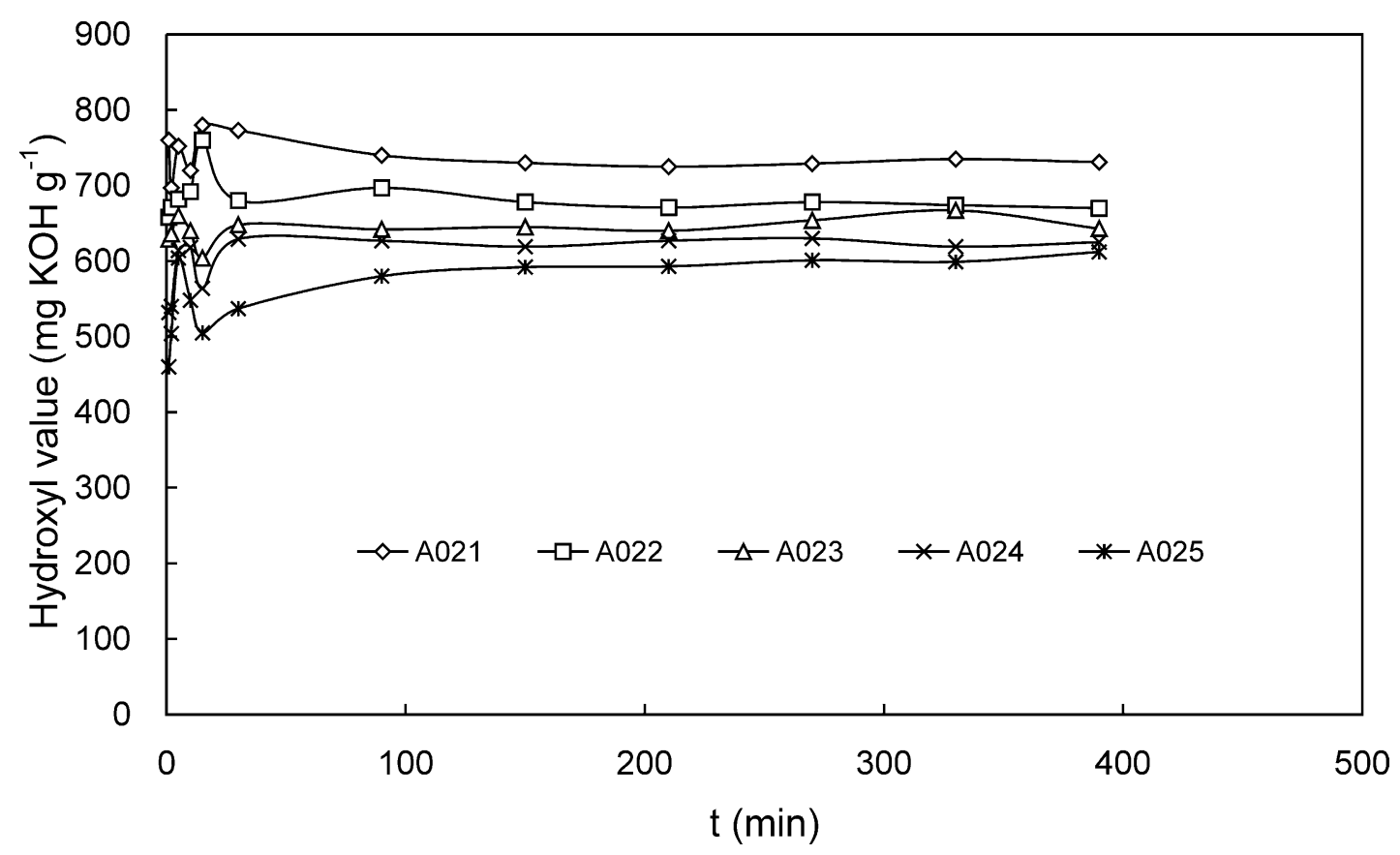

Fig. 1. Variation in hydroxyl value of glycolysis products with reaction times $(t)$ at $\mathrm{DEG} / \mathrm{PU}=150 \%$. A021, A022, A023, A024, A025: KAc/PU $=5$, $2,1,0.5,0 \%$. 
value for the ratio $\mathrm{KAc} / \mathrm{PU}=0$ and for $\mathrm{DEG} / \mathrm{PU}=50 \%$ is very high with respect the original polyols (listed in Table 1). The hydroxyl value reaches constant values, when $\mathrm{KAc} / \mathrm{PU}=1 \%$ for three DEG concentrations. For the same reaction time, the conversions of $-\mathrm{NCOO}-$ are about in the ranges of 95.4-98.9, 88-94.9, and 59.4$76 \%$ for $\mathrm{DEG} / \mathrm{PU}=250,150$, and $50 \%$, respectively. The presence of DEG and KAc enhances the conversion of - NCOO- and thus the glycolysis of PU, which is consistent with the increasing hydroxyl value. At a reaction time of $90 \mathrm{~min}$, the conversion of $-\mathrm{NCOO}-$ for $\mathrm{DEG} / \mathrm{PU}=150 \%$ is close to those for $\mathrm{DEG} / \mathrm{PU}=250 \%$ and much higher than those for $\mathrm{DEG} / \mathrm{PU}=50 \%$. The $M_{\mathrm{w}}$ at a reaction time of $90 \mathrm{~min}$ are in the ranges of $443-560$, 564-652, and 580-748 for DEG/PU $=250$, 150 , and $50 \%$, respectively. Higher DEG and KAc concentrations result in a lower molecular weight. These values reach nearly constant values at $\mathrm{KAc} / \mathrm{PU}=1 \%$ for three DEG concentrations. The viscosity of the glycolysis products for a reaction time of $90 \mathrm{~min}$ is shown in Fig. 8. These values are in the range of about 633$3,601 \mathrm{cps}$. The viscosities of glycolysis products for $\mathrm{DEG} / \mathrm{PU}=150 \%$ are close to those for $\mathrm{DEG} / \mathrm{PU}=100$ and $50 \%$. Examining Figs. 1, and 3-8, the optimum reaction condition with the mass ratios of DEG/ $\mathrm{PU}=150 \%$ and $\mathrm{KAc} / \mathrm{PU}=1 \%$, and the reaction time $=90$ min may be obtained.

\subsection{Purification of liquid products}

Glycolysis products consist mostly of polyol-containing materials (liquid products) together with a small

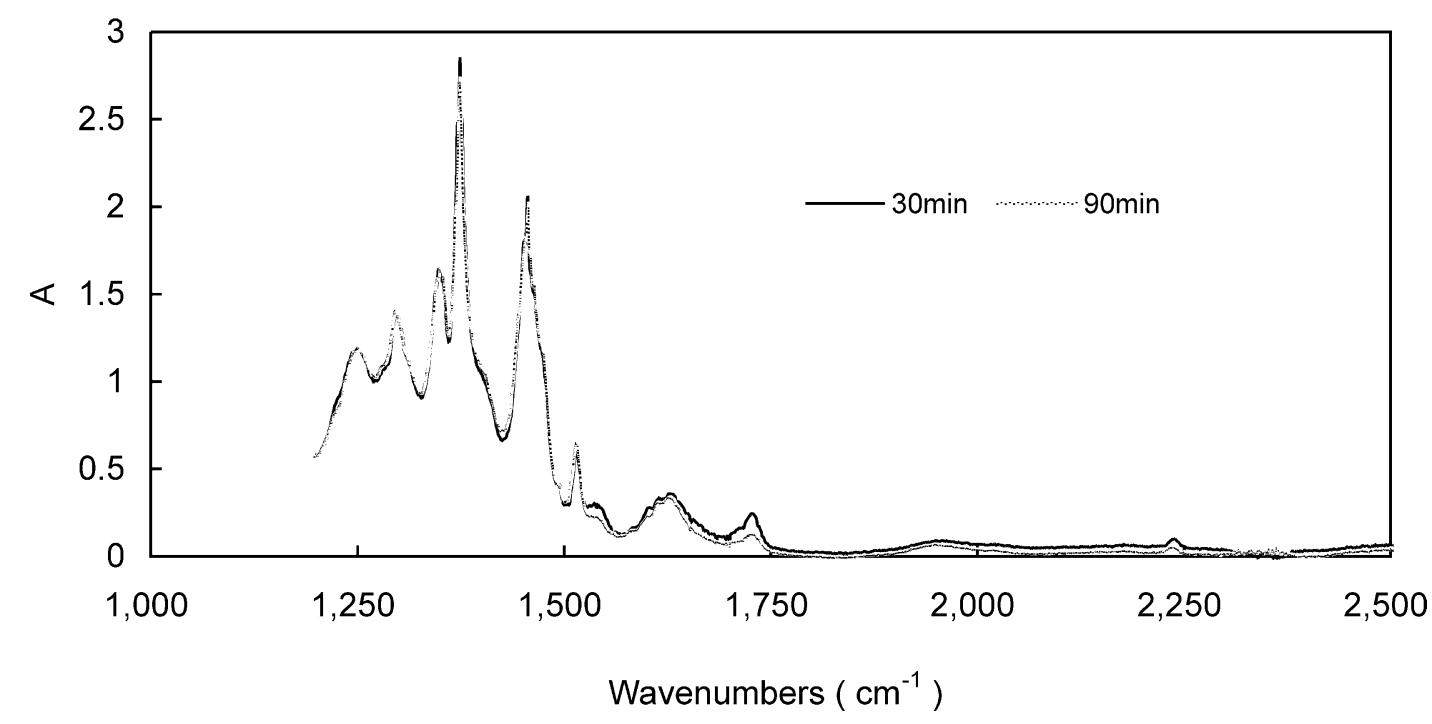

Fig. 2. Variation in FTIR spectrum of glycolysis products with reaction times $(t)$ at DEG $/ \mathrm{PU}=150 \%$ and $\mathrm{KAc} / \mathrm{PU}=1 \%$.

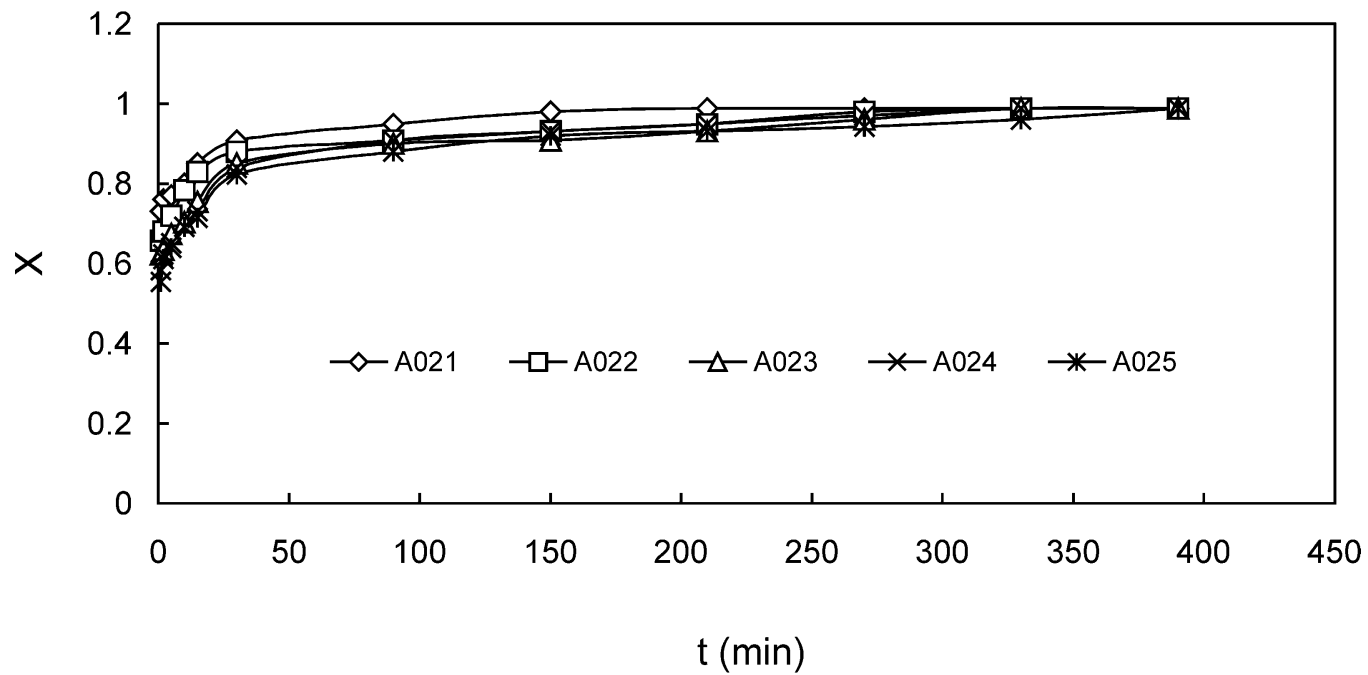

Fig. 3. Variation in conversion $(\mathrm{X})$ of $-\mathrm{NCOO}-$ in $\mathrm{PU}$ with reaction times at DEG/PU $=150 \%$. A021, A022, A023, A024, A025: KAc/PU $=5,2,1$, $0.5,0 \%$. 
fraction of gaseous products, such as $\mathrm{CO}_{2}$ and hydrocarbons. The gaseous products at the top of reactor were first cooled with a condenser and then adsorbed by an active carbon filter before being vented to a fume hood. After the glycolysis $(t=400 \mathrm{~min})$, the mass percentages of liquid products remaining in the reactor are about $87.9-92.67 \%$ for all the experimental runs. As indicated in the results of the analysis of the glycolysis products properties, adequate concentrations of DEG and KAc, and an adequate reaction time are $150 \%$ and $1 \%$, and $90 \mathrm{~min}$, respectively. The glycolysis products for the experimental runs of A016 (DEG/PU $=200 \%$, $\mathrm{KAc} / \mathrm{PU}=2 \%), \quad \mathrm{A} 017 \quad(\mathrm{DEG} / \mathrm{PU}=200 \%, \quad \mathrm{KAc} /$ $\mathrm{PU}=1 \%), \mathrm{A} 022(\mathrm{DEG} / \mathrm{PU}=150 \%, \mathrm{KAc} / \mathrm{PU}=2 \%)$,
$\mathrm{A} 023(\mathrm{DEG} / \mathrm{PU}=150 \%, \mathrm{KAc} / \mathrm{PU}=1 \%), \mathrm{A} 026(\mathrm{DEG} /$ $\mathrm{PU}=100 \%, \mathrm{KAc} / \mathrm{PU}=2 \%), \mathrm{A} 027(\mathrm{DEG} / \mathrm{PU}=100 \%$, $\mathrm{KAc} / \mathrm{PU}=1 \%$ ) at $t=90 \mathrm{~min}$ were thus collected and distilled to investigate the properties of the distilled materials (polyol-containing liquid products). The recovery of polyol-containing liquid products is shown in Fig. 9. The polyol-containing products are mostly in a temperature range of $245-260^{\circ} \mathrm{C}$ (gas phase temperature). The total yields of the distilled materials (polyolcontaining liquid products) are 53.1, 59.9, 50, 55.4, 38.9, and $24.5 \%$ for the experimental runs A016, A017, A022, A023, A026, and A027, respectively. The $M_{\mathrm{w}}$ of the polyol-containing liquid products are about 157 395. Because the high molecular-weight residues

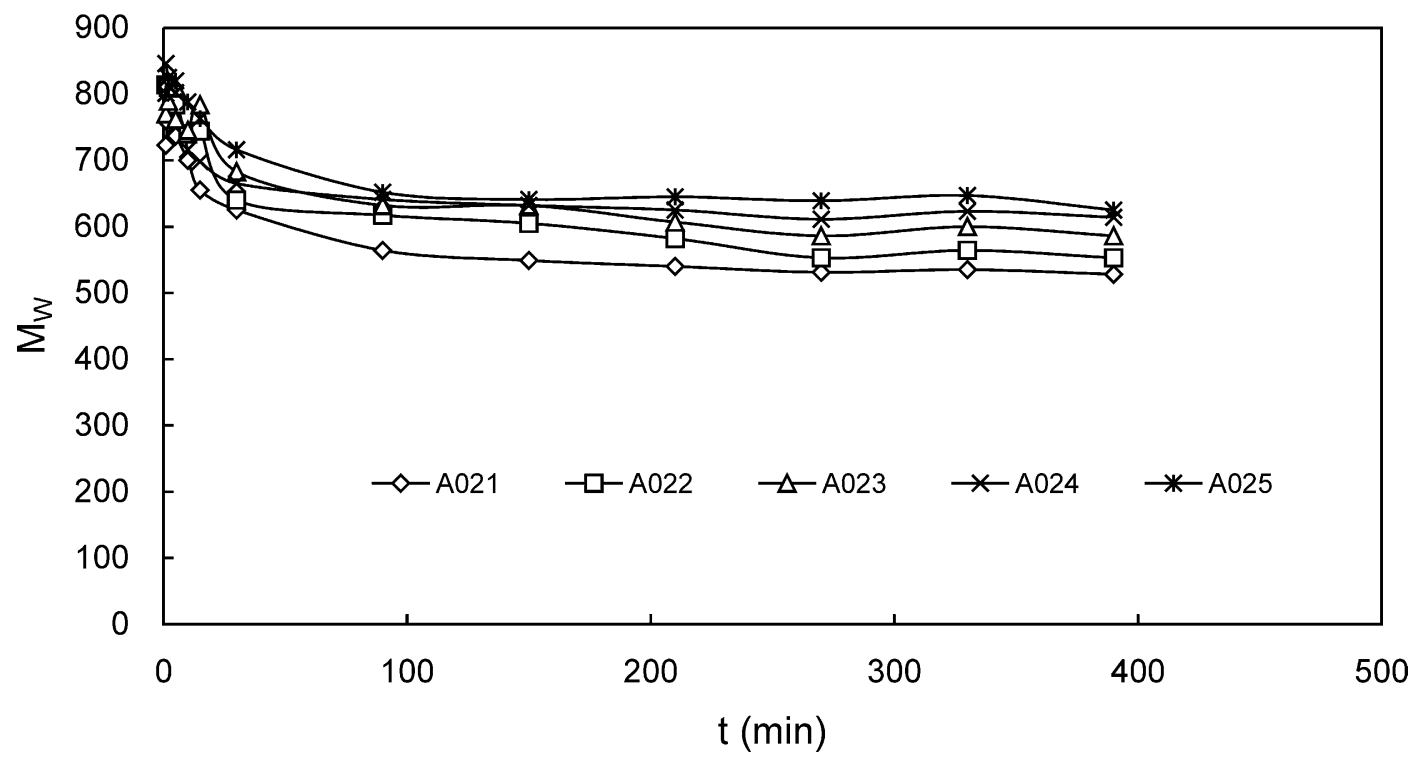

Fig. 4. Variation in weight average molecular weight $\left(M_{\mathrm{w}}\right)$ of glycolysis products with reaction times $(t)$ at DEG/PU $=150 \%$. A021, A022, A023, $\mathrm{A} 024, \mathrm{~A} 025: \mathrm{KAc} / \mathrm{PU}=5,2,1,0.5,0 \%$.

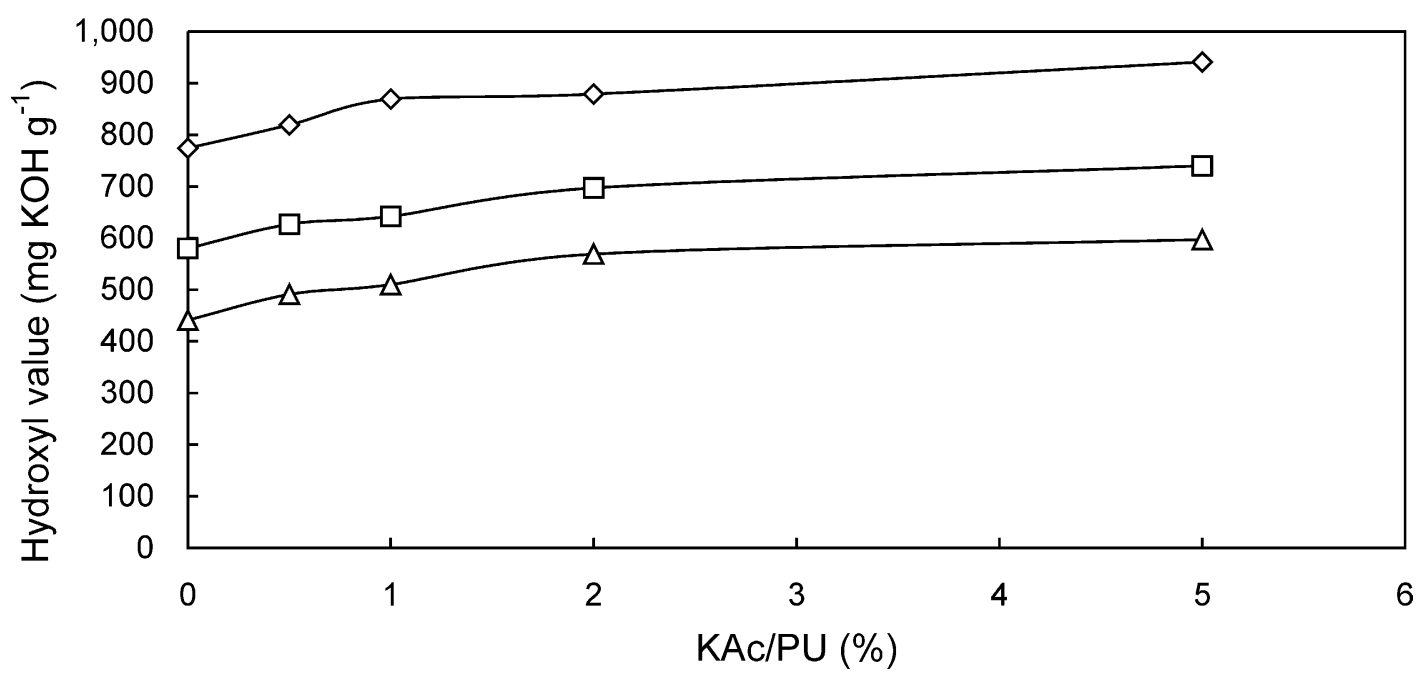

Fig. 5. Variation in hydroxyl value of glycolysis products at $t=90 \mathrm{~min}$ with concentration of catalyst (KAc/PU). $\diamond$ and $\square$ and $\triangle$ concentrations of $\mathrm{DEG} / \mathrm{PU}=250,150,50 \%$, respectively. 


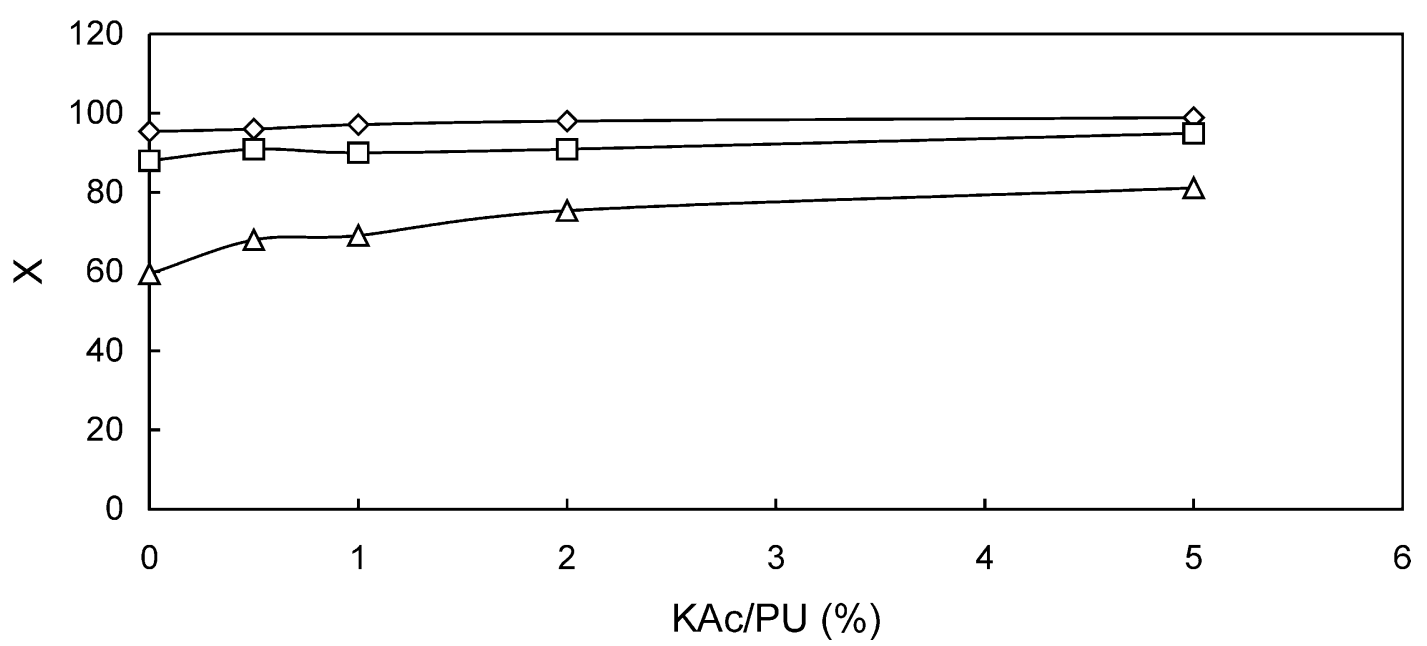

Fig. 6. Variation in conversion (X) of $-\mathrm{NCOO}-$ in PU at $t=90$ min with concentration of catalyst (KAc/PU). $\diamond$ and $\square$ and $\triangle$ concentrations of $\mathrm{DEG} / \mathrm{PU}=250,150,50 \%$, respectively.

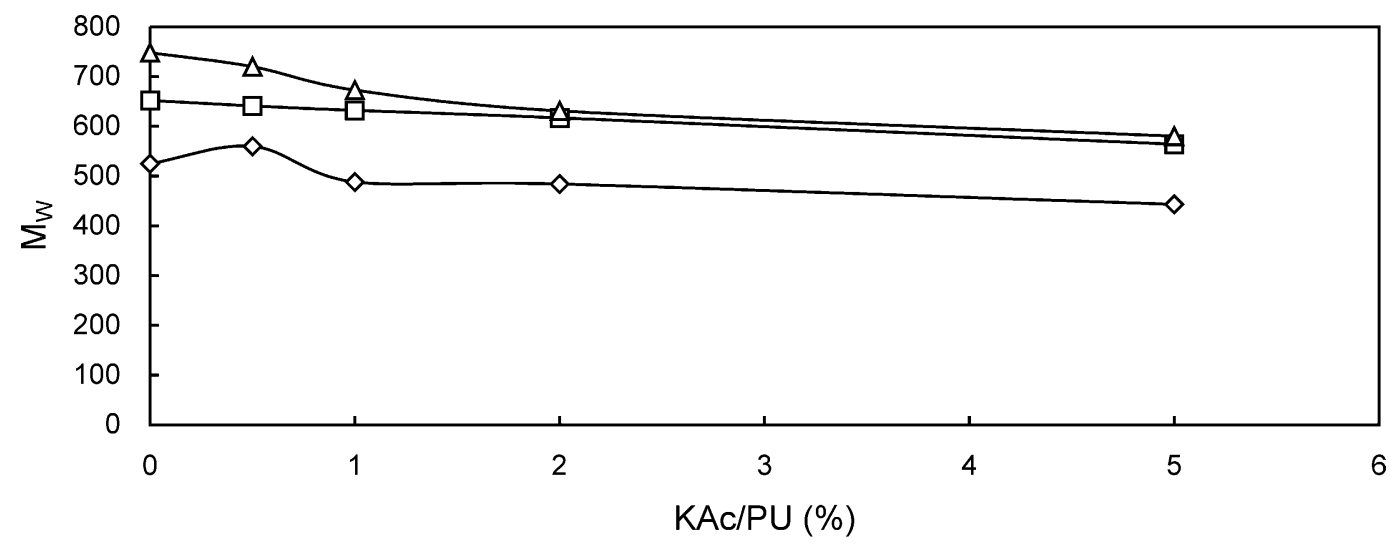

Fig. 7. Variation in weight average molecular weight $\left(M_{\mathrm{W}}\right)$ of glycolysis products at $t=90 \mathrm{~min}$ with concentration of catalyst (KAc/PU). $\diamond$ and $\square$ and $\triangle$ concentrations of $\mathrm{DEG} / \mathrm{PU}=250,150,50 \%$, respectively.

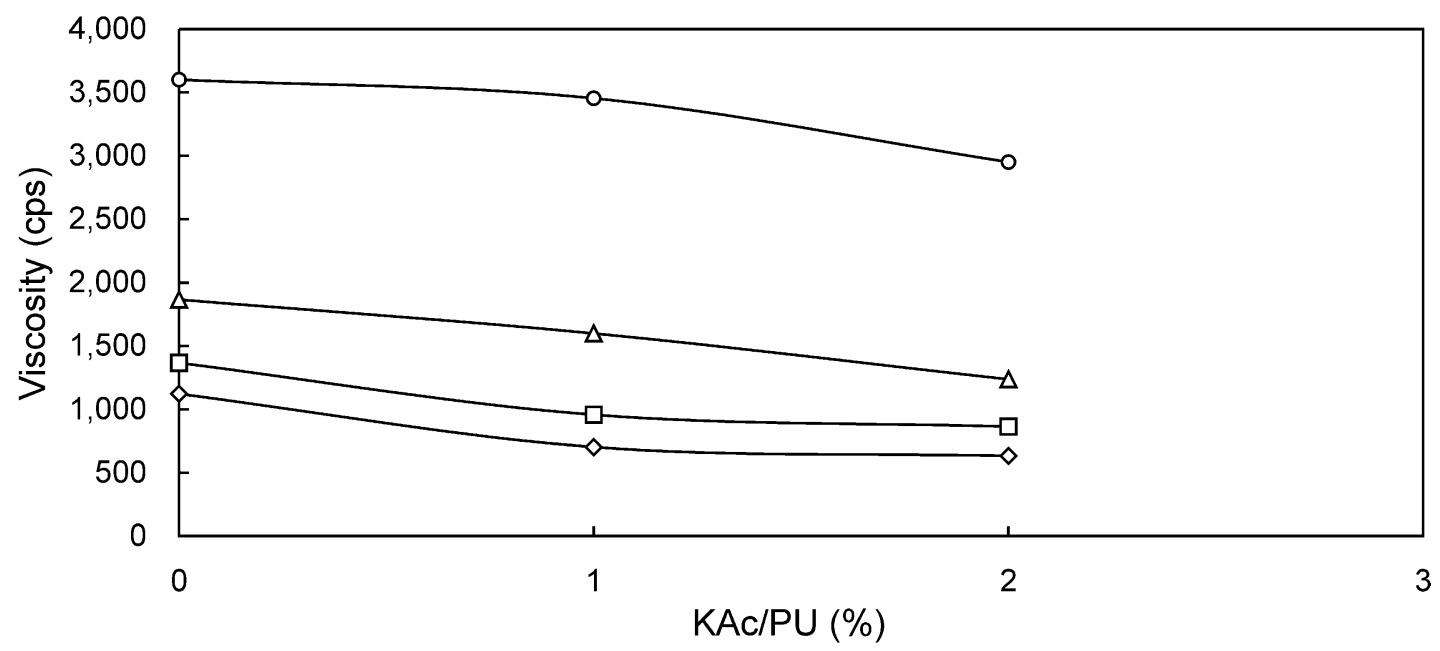

Fig. 8. Variation in viscosity (measured at $25 \pm 0.1^{\circ} \mathrm{C}$ ) of glycolysis products at $t=90$ min with concentration of catalyst (KAc/PU). $\diamond$ and $\square$ and $\triangle$ concentrations of $\mathrm{DEG} / \mathrm{PU}=250,150,50 \%$, respectively. 


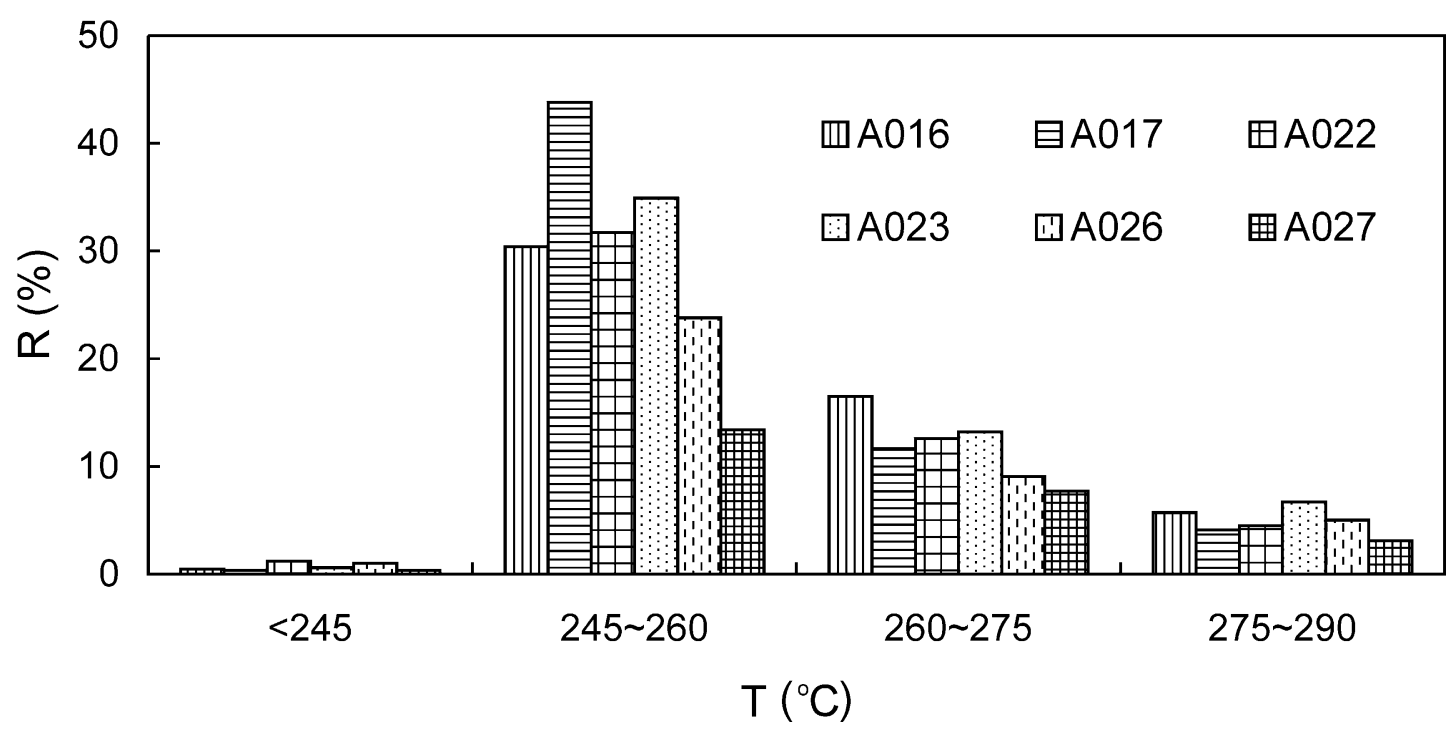

Fig. 9. Recovery $(R)$ of polyol-containing liquid products at different distillation temperatures $(T)$.

remained in the still after $T>290{ }^{\circ} \mathrm{C}$, the $M_{\mathrm{w}}$ of the polyol-containing liquid products is much lower than those of the original liquid products (shown in Fig. 4). The hydroxyl values of the polyol-containing liquid products are about $863-1021 \mathrm{mg} \mathrm{KOH} \mathrm{g}^{-1}$, similar to that of DEG (1057.3 $\left.\mathrm{mg} \mathrm{KOH} \mathrm{g}^{-1}\right)$, thereby indicating that the distilled materials may consist of excess DEG or the DEG-containing polyol may be produced from the glycolysis of rigid PU foam. Also, undesirable secondary products may be formed during the glycolysis reaction. The most common side products is diphenylmethanediamine (MDA) which is formed by the presence of water in the reaction phase [3]. The presence of glycolysis products with amine groups could modify the hydroxyl number with respect to the theoretical value. Moreover it they are free they could make the product very dangerous. Generally, these products must be removed through distillation or purified by batch-wise washing with clean DEG to remove MDA impurities [3].

\section{Conclusions}

Glycolysis of flexible PU foam has been investigated to provide useful data for the recycling of waste cars. The experiments were performed under atmospheric pressure in a stirred flask kept at a constant temperature by a heating mantle. DEG and KAc were used as solvent and catalyst in the glycolysis system, respectively. The properties of glycolysis products such as hydroxyl value, weight average molecular weight, viscosity, and the conversion of the $-\mathrm{NCOO}$ - functional group in $\mathrm{PU}$ at different experimental conditions were analysed. Adequate concentrations of DEG and KAc, and an adequate reaction time have been determined. The recovery of polyol-containing liquid products can be achieved by the distillation of glycolysis products. However, further study on recycling waste PU foams will certainly be helpful. Such research needs to include (1) determining the amount (ratio) of DEG consumed for different reaction conditions, (2) investigating the possibility for recycling the polyols-containing products as solvents instead of pure DEG, (3) analyzing the properties of the new foams prepared from the recycled polyols, and (4) investigating the effects of water on the properties of the glycolysis products.

\section{Acknowledgements}

We express our sincere thanks to the National Science Council of Taiwan for the financial support under project NSC 89-2211-E-212-002 and also would like to thank the Huntsman Polyurethanes Co., Ltd, of Taiwan, for providing the PU sample.

\section{References}

[1] Hooper JFG, Parrinello G, Parfondry A, Kroesen KW. Cell Polym 1992;11(5):388-96.

[2] Hicks DA, Krommenhoek M, Soderberg DJ, Hopper JFG. Cell Polym 1994;13(4):259-76.

[3] Scheirs J, editor. Polymer recycling. UK: John Wiley \& Sons; 1998. p. 339-77.

[4] Hartel JJ. New developments in thermoset recycling and environmentally friendly processing systems. In: Proceedings of Polyurethanes World Congress, 10-13 October 1993. p. 218-23.

[5] Van der Wal HR. J Reinf Plast Compos 1994;13:87-96.

[6] Kerscher J, Schwager H, RaBhofer W, Pfefferkorn R. Utech 1996;22:1-10. 
[7] Simioni F, Modesti M. Cell Polym 1993;12(5):337-48.

[8] Modesti M, Simioni F, Munari R, Baldoin N. React Funct Polym 1995;26:157-65.

[9] Borda J, Pasztor G, Zsuga M. Polym Degrad Stab 2000;68:41922.

[10] Troev K, Grancharov G, Tsevi R, Tsekova A. Polymer 2000; 41:7017-22.
[11] Modesti M, Simioni F, Rienzi SA. J Elast Plast 1992;24(4):288-305.

[12] Simioni F, Modesti M, Rienzi SA. Cell Polym 1987;6(6):27-41.

[13] Gassan M, Naber B, Neiss V, Moeckel P, Weissflog W. US Patent 5357006; 1994.

[14] Wu CH, Chang CY, Li JK. Polym Degrad Stab 2002;75:413-21.

[15] Wu CH, Chang CY, Li JK, Ho KS. J Chinese Inst Environ Engrg 2002;12(2):157-65. 